\title{
Cartilha Ada e Edu: \\ de produção regional à circulação \\ nacional $(1977-1985)^{*}$
}

\author{
CANCIONILA JANZKOVSKI CARDOSO
}

Universidade Federal de Mato Grosso

\section{CIRCUNSCREVENDO O OBJETO DE ESTUDO, SUA METODOLOGIA E FONTES}

Neste trabalho são apresentados parte de resultados de pesquisa cujo objetivo geral foi o de contribuir para a constituição, sistematização e socialização da história de um livro mato-grossense, mediante a investigação da produção, difusão e circulação da cartilha Ada e Edu, que foi elaborada por professoras de Mato Grosso, no ano de 1977. Trata-se de uma investigação inscrita na história da alfabetização, campo caracterizado por Antônio Frago (1993, p. 81) pelos termos ruptura e abertura, desagregação e explosão. Para esse autor, "A história da alfabetização mantém relação com, interessa-se por e abriu-se a campos e questões tão diversos - mas todos conectados - que finalmente parece ter-se diluído”. Essa área de estudo interdisciplinar e confluente é, segundo Magda Soares e Francisca Maciel (2000), ainda nova no Brasil. Em meio à diversidade, abertura e diluição do assunto, esta investigação, fruto de pesquisa de pós-doutorado, ${ }^{1}$ tem como foco a história dos

* Trabalho revisto e ampliado, inicialmente apresentado na 33a Reunião Anual da Asso-
ciação Nacional de Pós-Graduação e Pesquisa em Educação (ANPEd), em 2010, no
Grupo de Trabalho Alfabetização, Leitura e Escrita (GT-10).
1 A pesquisa foi realizada na Universidade Federal do Paraná (UFPR), no Grupo de
Pesquisa Cultura, Práticas Escolares e Educação Histórica, sob a orientação da 
livros escolares, tomando como objeto de análise o funcionamento do circuito que foi organizado em torno de um deles no contexto escolar mato-grossense.

Imediatamente, surgiram as questões: Por que estudar livros escolares? Qual a contribuição de um estudo dessa natureza? Uma resposta possível abrange a constatação de que, em 2009, o governo federal investiu $\mathrm{R} \$ 689,4$ milhões na compra e distribuição de 103.581.176 livros didáticos para a educação básica, beneficiando 28.968.104 estudantes. A história evidencia que desde a criação do Instituto Nacional do Livro (INL), em 1929, o livro didático tem circulado em escala crescente no cenário nacional. Essa "onipresença” do livro didático (Choppin, 2004, p. 551) abre importante dimensão no campo da investigação do fenômeno da cultura escrita. Apresentando "multiplicidade de funções", "diversidade de agentes" (idem, p. 552) e ainda se configurando como documento multifacetado, o livro didático é elemento fundamental na constituição/manutenção da cultura material escolar. Assim, o estudo do livro didático oferece referenciais importantes para se pensar práticas educativas contemporâneas, relacionadas aos usos da cultura escrita escolar e, sobretudo, ao papel formador que exerce sobre seus destinatários: professores e alunos. Em decorrência, o estudo histórico de cartilhas ajuda-nos a compreender o passado, para explicá-lo, e também iluminar o presente, observando-se tensões, mudanças e permanências, características da alfabetização no Brasil.

Outra motivação para o estudo respalda-se em Amâncio (2008), que ressalta a ausência de produção e publicação de cartilhas de ensino de leitura em Mato Grosso nas primeiras décadas do século XIX. Sendo $A d a$ e Edu a única produção encontrada até o início desta pesquisa, era justificável que se transformasse em objeto de estudo.

A proposta metodológica desta investigação tomou como base o "circuito das comunicações" - modelo proposto por Robert Darnton (1990) - para examinar o percurso da produção mato-grossense Nossa terra nossa gente, posteriormente transformada na cartilha $A d a$ e Edu, editada e comercializada nacionalmente pela Bloch Editores. Também para Darnton, a história dos livros é hoje um campo de estudo rico e diversificado, cuja principal peculiaridade é a convergência de diversas disciplinas. A percepção da complexidade que envolve o assunto o leva a propor um modelo geral "para analisar como os livros surgem e se difundem entre a sociedade", como forma de mapear a busca e ajudar o pesquisador, em especial o iniciante, a "enxergar o objeto como um todo" (idem, p. 112).

Para esse autor (idem, ibidem),

[...] os livros impressos passam aproximadamente pelo mesmo ciclo de vida. Este pode ser descrito como um circuito de comunicação que vai do autor ao editor (se não é o livreiro que assume esse papel), ao impressor, ao distribuidor, ao vendedor, e chega ao leitor. O leitor encerra o circuito porque ele influencia o autor tanto antes quanto depois do ato de composição.

professora doutora Tânia Maria Figueiredo Braga; contou com o financiamento do Conselho Nacional de Desenvolvimento Científico e Tecnológico (CNPq). 
O modelo permite construir uma visão holística da história do livro, na medida em que abre a possibilidade de análise dos diferentes segmentos que compõem o seu ciclo de vida.

A periodização eleita nesta investigação contemplou o ano de 1977, que marca a data da produção da cartilha Nossa terra nossa gente, depois transformada em Ada e Edu, até o ano de 1985, data da última edição encontrada.

O caminho investigativo encontra-se orientado por referenciais teórico-metodológicos ligados à história cultural, à história das disciplinas escolares e, mais precisamente, à história dos livros, os quais permitem abordar a elaboração e a circulação de um impresso em um contexto abrangente e multifacetado.

Para tentar chegar ao mundo do passado, recorri às fontes históricas, entendidas como "produções humanas", quer sejam as que, aparentemente, "se constituem de modo espontâneo" ou "aquelas que produzimos intencionalmente" (Saviani, 2004, p. 6). Desse modo, compreendendo e antecipando o valor lacunar das fontes impressas que seriam encontradas, recorri também às memórias das autoras e de algumas alfabetizadoras - leitoras/usuárias - da cartilha Ada e Edu. Entendendo que

A memória é um elemento essencial do que se costuma chamar de identidade, individual ou coletiva, cuja busca é uma das atividades fundamentais dos indivíduos e das sociedades de hoje, na febre e na angústia. [...] A memória, na qual cresce a história, que por sua vez a alimenta, procura salvar o passado para servir ao presente e ao futuro. (Le Goff, 2003, p. 469; 471, grifo do original)

$\mathrm{Na}$ busca das fontes impressas, visitei acervos locais e nacionais, ${ }^{2}$ bem como realizei contatos em diferentes órgãos relacionados ao livro didático brasileiro. ${ }^{3} \mathrm{Já}$ as fontes orais, utilizadas na perspectiva de "memória” de Jacques Le Goff (2003), são oriundas de entrevistas realizadas com seis autoras, quatro professoras/usuárias, duas supervisoras e uma coordenadora do Programa do Livro Didático para o Ensino Fundamental (PLIDEF) de Mato Grosso, sujeitos que gravitaram em torno da cartilha. Trabalhei, ainda, com os depoimentos escritos de Nívia Gordo, consultora da Secretaria de Educação/MT no período em que $A d a$ e Edu foi

2 Acervos visitados: 1. Arquivo Público do Estado de Mato Grosso (APMT); 2. Biblioteca Nacional - RJ; 3. Arquivo Central da Secretaria de Estado de Educação (SEDUC/MT); 4. "Arquivo" da Bloch Editores - RJ; 5. Arquivo Administrativo do Ministério da Educação (MEC) - Brasília; 6. Centro de Informação e Biblioteca em Educação (CIBEC) - Brasília; 7. Arquivo do Instituto Nacional de Estudos e Pesquisas Educacionais Anísio Teixeira (INEP) - Brasília; 8. Centro de Documentação do Núcleo de Pesquisa em Educação da Universidade Federal de Mato Grosso (NUPED/UFMT); 9. Acervo da Escola Daniel Martins de Moura (Rondonópolis-MT).

3 Órgãos contatados: 1. Fundo Nacional de Desenvolvimento da Educação (FNDE); 2. Secretaria de Educação Básica (SEB); 3. Programa Nacional do Livro Didático; 4. Coordenação Geral de Avaliação de Materiais (COGEAM); 5. Coordenação de Avaliação e Qualidade do Livro Didático; 6. Secretaria de Biblioteca (SBIB) do Senado Federal. 
elaborada, e com o de Arnaldo Niskier, diretor da Bloch Editores no período em que a cartilha foi editada.

Dos resultados obtidos a respeito do circuito da comunicação da obra em questão, apresento neste texto um recorte que contempla aspectos relacionados à sua produção e circulação regional e nacional. ${ }^{4}$

\section{CONTRIBUIÇÕES DOS ESTUDIOSOS: ARTICULANDO VOZES INTERDISCIPLINARES}

Para André Chervel (1990), um dos precursores da história das disciplinas escolares, a especificidade desse campo reside na investigação dos ensinos da idade escolar, pois o seu elemento central é a história dos conteúdos. Nessa história confrontam-se as finalidades da escola e as transformações do público escolar, originando as evoluções e adaptações das disciplinas escolares. "Fruto de um diálogo secular entre os mestres e os alunos, elas constituem, por assim dizer, o código que duas gerações, lentamente, minuciosamente, elaboraram em conjunto para permitir a uma delas transmitir à outra uma cultura determinada" (idem, p. 222). O código ou o conjunto de conhecimentos, valores e métodos se expressa nas propostas de cursos, nos programas de ensino, nos periódicos pedagógicos e, principalmente, nos manuais didáticos. Nesses últimos se verifica o que Chervel denomina de vulgata, ou seja, aspectos comuns às diferentes disciplinas. Assim, "os conceitos ensinados, a terminologia adotada, a coleção de rubricas e capítulos, a organização do corpus de conhecimentos, mesmo os exemplos utilizados ou os tipos de exercícios praticados são idênticos, com variações aproximadas" (idem, p. 203).

Essas considerações sobre os conteúdos das disciplinas escolares elevam para um plano privilegiado a análise dos manuais e das edições didáticas, ou seja, a história dos livros escolares.

Em artigo publicado originalmente em 2002, Alain Choppin apresenta um balanço da produção mundial sobre a história dos livros e das edições didáticas. Em que pesem os argumentos sobre as dificuldades de se fazer um "estado da arte exaustivo sobre o que foi feito e escrito" (Choppin, 2004, p. 549), seu trabalho tornou-se um texto fundador na medida em que mapeia os principais temas e problemáticas abordados pela pesquisa histórica, além de destacar tendências e perspectivas para esse campo de estudo. Aspectos como "o peso que o setor escolar assume na economia editorial nesses últimos dois séculos" e "a multiplicidade dos agentes envolvidos em cada uma das etapas que marcam a vida de um livro escolar, desde a sua concepção pelo autor até seu descarte pelo professor e, idealmente, sua conservação para as futuras gerações" (idem, p. 551-554), são apontados pelo

4 O relatório detalhado dessa investigação encontra-se em vias de publicação pela Editora da Universidade Federal de Mato Grosso (EdUFMT), financiada pela Fundação de Amparo à Pesquisa do Estado de Mato Grosso (FAPEMAT), com o título Cartilha Ada e Edu: produção, difusão e circulação (1977-1985). 
autor como forma de justificar a relevância do balanço, evidenciando a variedade de aspectos passíveis de serem abordados pela pesquisa histórica sobre livros e edições didáticas.

Mas, afinal, como conceituar livro didático? Antônio Batista (2002, p. 534, grifos do original) inicialmente o define como "aquele livro ou impresso empregado pela escola, para desenvolvimento de um processo de ensino ou de formação". Logo, porém, a definição se revela pouco eficaz para conceituar um objeto variável e instável, que se apresenta em diferentes portadores impressos, resultando na impossibilidade de identificar "livro" didático ao objeto "livro" como comumente o conhecemos. O exemplo dado pelo autor é justamente o de cartilhas utilizadas no Brasil, entre o final dos anos de 1940 e meados de 1970, que se fazem acompanhar de outros objetos que não o livro (cartazes, folhas, fichas) e por ele denominados "satélites". Sabemos que o livro didático, embora seja um dos principais recursos utilizados pelos professores em suas práticas pedagógicas, é considerado "o primo-pobre da literatura, texto para ler e botar fora, descartável porque anacrônico: ou ele fica superado dados os progressos da ciência a que se refere ou o estudante o abandona, por avançar em sua educação"(Lajolo; Zilberman, 1998, p. 120). Antônio Batista lembra que o livro didático é voltado para o mercado escolar, destinando-se a um público infantil. Assim, é produzido em grandes tiragens de pouca qualidade material, o que o torna mais vulnerável à deterioração, sendo sua circulação predominante fora do espaço das grandes livrarias e bibliotecas. Para o autor (Batista, 2002, p. 529-530), o desprestígio social do livro didático, que possui muitos indicadores, desprestigia também, "por contaminação, [...] aqueles que dele se ocupam, os pesquisadores neles incluídos".

Assim sendo, não é tarefa fácil ao pesquisador se propor a conhecer e analisar a evolução do livro didático no Brasil, mais difícil ainda quando se trata de cartilhas, material descartável ao final de cada ano letivo.

Talvez permaneça a pergunta: Por que livros? Respondo com Laurence Hallewell (1985, p. XXIX): "Procurar conhecer uma nação por meio de sua produção editorial é, mais ou menos, o mesmo que julgar uma pessoa por meio de sua caligrafia. [...] as duas podem ser muito reveladoras, pois nós somos como nos expressamos".

Desse modo, considerando as representaçôes como a pedra angular de uma abordagem da história cultural (Chartier, 1990, p. 23), concordo, igualmente, que "o terreno comum dos historiadores culturais pode ser descrito como a preocupação com o simbólico e suas interpretações" (Burke, 2005, p. 10). O "mundo das representações", moldado pelos diversos e contraditórios discursos, leva a pensar sobre as modalidades de apropriação dos materiais culturais. Este é, sem dúvida, um fértil caminho para se perceber distinções e diferenciações socioculturais, em termos de acesso, de desvios e, sobretudo, de práticas de utilização e consumo do material didático que busquei analisar.

Assim, sem descuidar dos documentos, na pesquisa tentei dar uma atenção especial às práticas, recorrendo ao conceito de cultura escolar proposto por 
Dominique Julia (2001, p. 10, grifos do original): “[...] como um conjunto de normas que definem conhecimentos a ensinar e condutas a inculcar, e um conjunto de práticas que permitem a transmissão desses conhecimentos e a incorporação desses comportamentos". O conceito de cultura escolar, que inclui o corpo profissional da escola - os professores chamados a obedecer às ordens -, parece ser pertinente a esta investigação, uma vez que o livro didático, ao mesmo tempo em que se configura como norma - conteúdos e comportamentos a serem ensinados -, materializa e incorpora diversas práticas, dependendo do uso que dele fazem/fizeram os professores e os alunos. Desse modo, os textos que compõem os livros escolares "são registros a serem decodificados", pois estão impregnados de saberes a inculcar e "que tiveram como instrumento de inculcação [sic] as práticas educativas escolares" (Corrêa, 2000, p. 19).

\section{NOSSA TERRA NOSSA GENTE: UM LIVRO À SOMBRA DE UM PROJETO}

Produzido por professores mato-grossenses no ano de 1977, o conjunto didático Nossa terra nossa gente, composto pela cartilha, livro do professor e caderno de atividades, apareceu como uma resposta das políticas públicas, nacional e local, ao problema do fracasso escolar. Nele encontram-se aspectos do contexto legislativo e regulador (Choppin, 2004, p. 561), que condicionou a existência, a estrutura e a produção dessa cartilha no II Plano Setorial de Educação e Cultura (II PSEC), lançado pelo Ministério da Educação e Cultura (MEC) e previsto para os anos de 1975-1979. O plano abrigava em uma de suas áreas - a de Inovação e renovação do ensino - o subprojeto "Desenvolvimento de novas metodologias aplicáveis ao processo ensino-aprendizagem do $1^{\circ}$ grau" (PNM). Nessa ocasião, vivíamos uma dramática situação relacionada com o rendimento do ensino em nosso país, traduzida pela expressão fracasso escolar: a sistemática evasão e repetência de nossas crianças. As taxas de evasão e repetência, no Brasil, chegavam a 56\%, na passagem da $1^{\text {a }}$ para a 2a série (Brandão et al., 1983, p. 22), ${ }^{5}$ estendendo-se para as séries seguintes. Num período da educação brasileira em que o governo da ditadura militar, iniciada em 1964, pretendia solucionar os problemas educacionais adotando a linha do desenvolvimento internacional baseado no "capital humano", o II PSEC não poderia deixar de refletir uma filosofia liberal, que via a educação como investimento e como instrumento de mudança social. Assim, os objetivos e metas do II PSEC refletiam as concepções de racionalidade, eficiência e produtividade necessárias a uma educação vista como "instrumento para a formação do que se convencionou chamar de 'recursos humanos' para o desenvolvimento" (Brasil, 1976, p. 22).

5 Atualmente, os índices de evasão e repetência continuam altos - 19,5\% no nível nacional -, o que demonstra uma enorme inadequação entre a demanda e a qualidade da oferta (Brasil, 1996-2002). 
A Secretaria de Educação e Cultura do Estado de Mato Grosso (SEDUC) acatou as proposições do II PSEC, em especial no que diz respeito ao PNM. As normas sugeriam que o subprojeto deveria, para enfrentar as reprovações na $1^{\mathrm{a}}$ série e regularizar o fluxo escolar, partir de estudos e experimentações com o intuito de desenvolver novas metodologias para subsidiar as unidades federadas, visando a uma maior aprendizagem, principalmente quanto à leitura e à escrita. Os dados da matrícula inicial e do desempenho dos alunos mato-grossenses no $1^{\circ}$ grau evidenciavam a gravidade da situação e a urgência em se tomar medidas direcionadas ao fracasso escolar. Evasão e repetência somavam o intolerável índice de 65,6\%.

Entre as atividades desenvolvidas no interior do PNM destaca-se a "experimentação de novas metodologias no ensino de $1^{\circ} \mathrm{Grau}$ e, em especial na $1^{\mathrm{a}}$ série, através de novos processos de alfabetização" (Mato Grosso, 1976, p. 8). Essa frente de trabalho foi desenvolvida nos anos de 1975 e 1976, com base em experiências de pesquisa "controlada" com diferentes métodos de ensino e cartilhas a eles correlatas. A reflexão sobre essas experiências levou a equipe responsável a decidir pela elaboração de uma cartilha regional. $\mathrm{Na}$ conclusão geral do relatório de 1976, a equipe assim se manifesta:

Partindo da dedução de que a aprendizagem seria mais eficaz se o professor empregasse uma cartilha que atendesse a esses aspectos e que fosse adequada à nossa realidade, esta coordenadoria juntamente com o Departamento de Educação, após consulta feita ao DEF/MEC, decidiu elaborar e aplicar para o ano de 1977 uma cartilha própria. (idem, p. 36)

A cartilha nasceu, portanto, da experiência da equipe da SEDUC no interior do PNM, alicerçada em uma "experimentação científica" que, apesar do esforço dos sujeitos envolvidos, não logrou os resultados esperados.

A equipe segue apresentando um conjunto de motivos que a levou a propor reformulações no PNM, entre elas:

1. elaboração de uma cartilha que atendesse aos requisitos da língua e à nossa realidade;

2. elaboração de um manual de orientação em linguagem simples e acessível do professor;

3. treinamento dos professores envolvidos no Projeto a fim de que eles fossem orientados para o emprego da cartilha, recebessem informações específicas relativas à língua portuguesa e aos pré-requisitos da alfabetização [...]. (Mato Grosso, 1977a, p. 10)

A decisão de elaborar uma cartilha estava ancorada no pressuposto básico de que, embora houvesse múltiplas interferências no processo de alfabetização, alguns fatores eram passíveis de "um acompanhamento e controle mais efetivos". O grupo então se decidiu pela seleção dos fatores cartilha e professor, que, "preparados adequadamente e bem controlados [sic], poderiam responder por uma elevação 
do padrão de ensino e, consequentemente, do rendimento escolar" (Mato Grosso, 1977a, p. 16).

Duas crenças importantes da equipe aparecem no documento Exposição de motivos (Mato Grosso, 1977b). Por um lado, a esperança em poder materializar uma cartilha ideal do ponto de vista linguístico: utilizando-se uma linguagem regional, próxima à linguagem dos escolares, e apresentando a língua de forma graduada, contemplando suas dificuldades e sua complexidade. Desse modo, na perspectiva da equipe, ela seria de fácil manejo pelo professor e de melhor apropriação pelos alunos. Por outro lado, pela definição dos objetivos e conteúdos inerentes à $1^{\mathrm{a}}$ série, a esperança de poder homogeneizar a aprendizagem das crianças.

É nesse contexto que nasceu a cartilha Nossa terra nossa gente, um livro didático que possuía estreitos vínculos com um projeto de política pública e com as concepções de educação e de alfabetização oficiais e/ou hegemônicas naquele momento histórico.

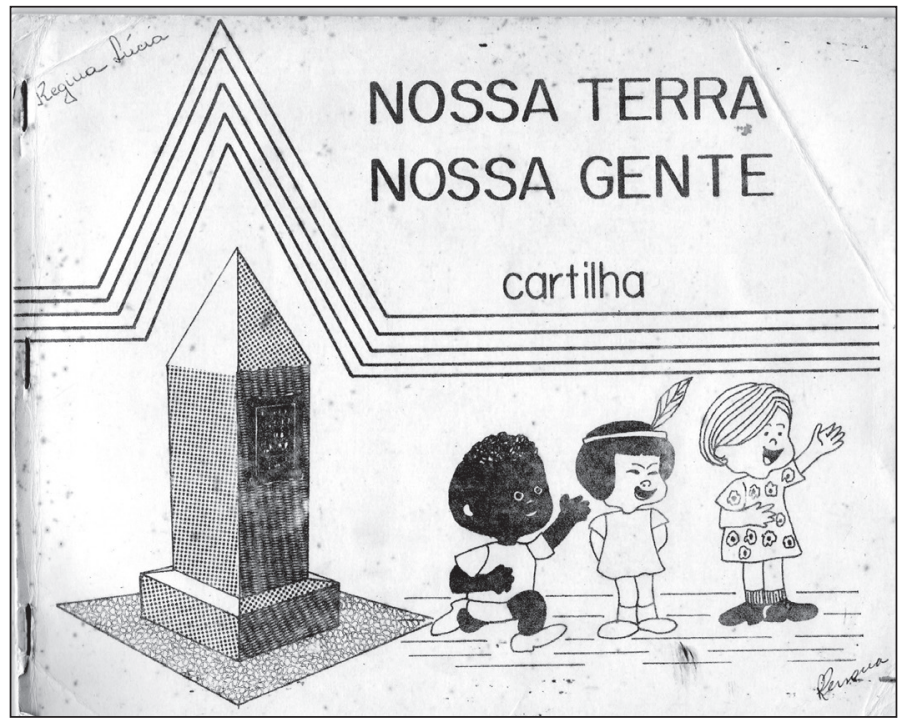

Figura 1 - Cartilha Nossa terra nossa gente.

Fonte: Acervo do Centro de Documentação do NUPED/UFMT.

\section{NOSSA TERRA NOSSA GENTE SE TRANSFORMA EM ADA E EDU: UMA CARTILHA DO MATO GROSSO PARA O BRASIL}

Em 1977, o PNM de Mato Grosso foi reconfigurado do ponto de vista metodológico, não seguindo mais a orientação de realizar pesquisa experimental. Nessa fase a equipe se dedica, fundamentalmente, a elaborar o conjunto didático, a cartilha e seus complementos, selecionar e preparar as escolas e os professores e aplicar o material elaborado, acompanhando a prática pedagógica passo a passo. 
Segundo uma das autoras,

Eu me lembro bem que a gente tinha muita consciência de que o projeto era um projeto-piloto, que a situação era uma situação de laboratório e que aquilo que desse resultado, a gente ia espalhar para o estado. (Maria Antonieta Fernandes) ${ }^{6}$

A partir daí, a equipe se dedicou a um projeto de alfabetização que se deu em torno da nova cartilha. Portanto, a circulação desse livro didático, em um primeiro momento, ocorreu entre os supervisores, professores e alunos do projeto-piloto, desenvolvido em Cuiabá, que visava à utilização do material em dois níveis: a) alunos com idade/série regular, tentando elevar os índices de promoção (Meta 1-PNM); b) alunos com distorção idade/série, tentando acelerar a escolarização (Meta 2-PNM). A Meta 1 foi desenvolvida nas mesmas escolas nas quais havia se realizado o "experimento" - Senador Azeredo; Professor Nilo Póvoas; José Machado N. da Costa; José Estevam -, acrescida da Escola Joaquina Caldas. Isso significa que os primeiros leitores da cartilha foram os 5 supervisores dessas escolas, os 17 professores (de vinte classes) e os 678 alunos atendidos nessas classes. A Meta 2 foi desenvolvida em 4 escolas, 11 classes, envolvendo 396 alunos e 11 professores. Esses professores e alunos também compuseram o quadro dos primeiros leitores de Nossa terra nossa gente (Mato Grosso, 1977a, p. 15; 30).

A notícia da existência da cartilha chegou a Arnaldo Niskier, então diretor da Bloch Editores, que procurou as autoras e fez um contrato de publicação, transformando Nossa terra nossa gente em Ada e Edu.

Os resultados do primeiro ano foram avaliados positivamente e em $1978 \mathrm{o}$ PNM se expandiu, passando a atuar em mais quatro municípios, além da capital, Cuiabá, a saber: Cáceres, Rondonópolis, Barra do Garças e Poxoréo. Essa ampliação atingiu 19 escolas, 68 classes da Meta 1, totalizando 2.272 alunos, e 48 classes da Meta 2, totalizando 1.259 alunos. Naquele ano, Ada e Edu já se encontrava publicada pela Bloch Editores, sendo esse o universo dos primeiros leitores do livro didático transformado, conforme citação abaixo:

Em todas as classes foi empregada a cartilha única "Ada e Edu" e o mesmo processo de alfabetização. Os supervisores, sob a coordenação da equipe central, acompanharam e controlaram sistematicamente o plano de alfabetização. (Mato Grosso, 1979a, p. 19)

A expansão teve continuidade no ano de 1979. Dados indicaram que o PNM em seu último ano de funcionamento envolveu 11 municípios. Na programação do III Encontro Estadual de Alfabetização (Mato Grosso, 1979b), aparecem listados para apresentar "relato de experiências" do projeto, além dos municípios já citados, outros seis: Alto Araguaia, Rosário Oeste, Poconé, Santo Antônio, Alto Paraguai e Guiratinga.

6 Entrevista realizada em 23 de abril de 2008. 
Esse quadro configura, portanto, a circulação da cartilha $A d a$ e $E d u$ no interior do PNM. A circulação em nível nacional esteve diretamente condicionada à edição do material pela Bloch Editores e pela entrada dessa cartilha no PLIDEF e, mais particularmente, no processo de coedição entre editoras e a Fundação Nacional de Material Escolar (FENAME), aspecto que será explorado a seguir.

\section{VOO INESPERADO: NOSSA TERRA NOSSA GENTE NO RIO DE JANEIRO}

Se atualmente o livro didático é questionado em alguns setores educacionais, na década de 1970 seu status deixava poucas dúvidas em relação à sua capacidade de promover uma organicidade à prática pedagógica. Em um arcabouço de valorização, o livro didático era visto como instrumento essencial, como tecnologia a serviço das ações educativas de sala de aula e, mesmo, para além dela. Em que pesem frequentes e históricas críticas aos métodos implementados por alguns livros didáticos ${ }^{7}$ ou, ainda, aos conteúdos nele abordados, o certo é que, por um lado, é justamete ao final daquela década que começam a aparecer, com mais intensidade, textos que condenariam o seu uso, ${ }^{8}$ acusando-o de ser um grande veículo ideológico, mas, por outro lado, é apenas na década de 1980 que esses textos ganham maior circulação e visibilidade entre os professores.

Entendido como uma importante peça do processo de ensino, o livro didático "sofre várias influências de natureza legal, técnica, política e organizacional decorrentes dos problemas gerais da educação e da escola" (Oliveira et al., 1984, p. 70). A década de 1970 foi fértil em mudanças com a Lei de Diretrizes e Bases da Educação Nacional (LDB) n. 5.692 além de outras medidas às quais o mercado editorial teve de se adaptar.

Segundo Oliveira et al. (idem, ibidem), a política mais geral do MEC, com respeito a currículos e programas de ensino, passava à época por grandes e contínuas mudanças, apresentando diretrizes muito genéricas. Essas políticas centrais eram complementadas por ações nos estados, por parte das secretarias ou conselhos de educação. Nesse sentido, "o critério para a edição de um texto é aproximá-lo das propostas curriculares dos estados. Mas elas são as mais deferentes. Não batem umas

7 Ver polêmica sobre cartilhas em Maria do Rosário Longo Mortatti (2000).

$8 \mathrm{Na}$ verdade, Fúlvia Rosemberg et al., no texto "Racismo em livros didáticos brasileiros e seu combate: uma revisão da literatura" (2003, p. 132), apontam que "Os estudos sobre preconceito racial e livros didáticos e paradidáticos no Brasil iniciaram-se na década de 1950 com a pesquisa de Dante Moreira Leite (1950): 'Preconceito racial e patriotismo em seis livros didáticos primários brasileiros”'. Os livros emblemáticos da década de 1980 são: As belas mentiras: a ideologia subjacente nos livros didáticos, de Maria de Lourdes Chagas Deiró Nosella (São Paulo: Moraes, 1981); Ideologia no livro didático, de Ana Lúcia Goulart de Faria (São Paulo: Cortez/Autores Associados, 1984); O livro didático em questão, de Barbara Freitag, Valéria Rodrigues Motta e Wanderly Ferreira da Costa (São Paulo: Cortez/Autores Associados, 1989). 
com as outras" (Scipione apud Oliveira et al., 1984, p. 71). Para resolver essa situação, "o que os autores e editores fazem é buscar um mínimo denominador comum" (idem, ibidem). Em muitos casos, as editoras oferecem mais de uma resposta: "Todas as editoras têm dois tipos de coleções. Uma coleção que serve para o Estado de São Paulo e uma que serve para o restante do Brasil" (Takahash apud idem, p. 72).

Segundo esse raciocínio, a Bloch Editores identificou em Nossa terra nossa gente esse mínimo denominador comum. Em sua avaliação, acreditou ser um livro que inspirava certo grau de aceitação por parte de professores de algumas regiões. Para isso, acionou seus dispositivos editoriais, independentemente de a produção ter sido inspirada numa adequação regional específica.

Em resposta à minha tentativa de conhecer como a Bloch Editores ficou sabendo da existência de Nossa terra nossa gente e se interessou em publicá-la, as autoras rememoraram e me apontaram a existência de dois “intermediários" (Darnton, 1990), o diretor da Bloch e a coordenadora do PLIDEF em Mato Grosso:

Por causa do PLIDEF, porque eles vinham muito aqui. O PLIDEF era o programa do livro didático, e através da Conceição, que era a coordenadora do PLIDEF [...] o Arnaldo esteve aqui em Cuiabá e viu a cartilha, e quando ele viu, falou assim: vamos publicar, entendeu? (Rosa Persona) $)^{9}$

Ficou explícito em várias falas que as autoras não tiveram um papel central na decisão de publicação. A ideia da publicação apareceu como uma agradável surpresa, um prêmio ou uma conquista. Em contrapartida, Niskier diz: "Lembro que fui o autor da ideia de buscar trabalhos originais em outros Estados, para diversificar a produção da Bloch Educação". ${ }^{10}$

Como se vê, Niskier e Conceição são atores que desempenharam papéis de agentes culturais, intermediários que foram entre uma produção local e as demandas do mercado de livros didáticos. Estavam inseridos em uma ampla rede de produtores e consumidores da literatura didática, tomando decisões pertinentes às demandas dessa rede.

Assim, a surpresa de ver, inesperadamente, Nossa terra nossa gente no Rio de Janeiro é explicada por Darnton (1990, p. 130-131) quando sugere que "os livros não respeitam limites, sejam linguísticos ou nacionais". Inserindo-os num circuito de comunicação, podemos "mostrar que os livros não se limitam a relatar a história: eles a fazem".

9 Entrevista realizada em 25 de abril de 2008.

10 Correspondência de 30 de março de 2005. 


\section{A COEDIÇÃO COM A FENAME E A CIRCULAÇÃO NACIONAL}

Comparando os conjuntos Nossa terra nossa gente e Ada e Edu, podemos perceber que a publicação da Bloch Editores, além do título, alterou o formato, o design e a qualidade do papel dos livros. O novo título foi retirado da primeira lição, cujas palavras-chave são Ada e Edu. Deixou-se de aludir a aspectos particulares (a terra e a gente de Mato Grosso) para oferecer ao leitor histórias de duas crianças comuns, que poderiam viver em qualquer lugar do Brasil. Do apelo étnico da capa da versão original, passou-se para a apresentação de crianças brancas, aparentemente, de classe média.

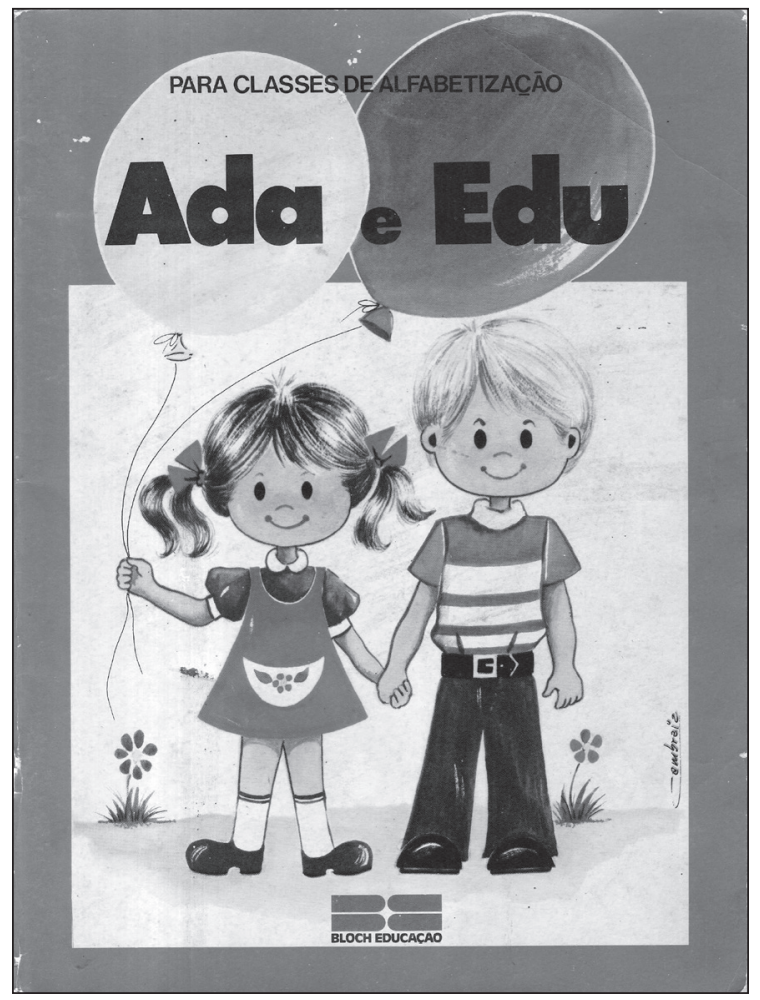

Figura 2 - Cartilha Ada e Edu, $1^{\text {a }}$ edição, 1978.

Fonte: Acervo do Centro de Documentação do NUPED/UFMT.

A 5a edição de $A d a$ e Edu, de 1981, coedição entre FENAME e Bloch, que abriu a possibilidade de circulação nacional dessa cartilha, deu-se no lapso de tempo em que "de censor oficial dos livros didáticos usados nas escolas brasileiras, o Estado foi assumindo também o papel de financiador desses livros" (Höfling, 2000, p. 163). O sistema de coedição com as editoras nacionais, com recursos do INL, foi implantado em 1970. Em 1983 é criada a Fundação de Assistência ao Estudante (FAE), e em 1984 deu-se fim ao sistema de coedição, passando o MEC 
a ser o comprador e distribuidor dos livros produzidos pelas editoras participantes do Programa do Livro Didático (PLID). ${ }^{11}$

O funcionamento do PLIDEF obedecia a uma complexa dinâmica, em torno da qual circulavam variadas instâncias e inúmeros intermediários, com o fim último de colocar em circulação, nas mãos de professores e alunos, uma determinada obra didática. Nesse estágio do circuito do livro, que aqui poderia ser chamado "penetração na distribuição estatal", o texto transitava entre editores, comissões avaliadoras do Departamento de Ensino Fundamental (DEF)/MEC, secretários de educação das unidades federadas, comissões avaliadoras das secretarias; técnicos em contabilidade da FENAME; impressores; revisores; distribuidores e livreiros; chegando, finalmente, aos leitores (bibliotecas, escolas e grande público) (Brasil, [197-?]).

Os dados sobre a política de produção e distribuição de livros didáticos da época, cruzados com os exemplares encontrados, me permitiram chegar a algumas conclusões e inferências a respeito das tiragens de $A d a$ e $E d u$, sintetizadas no quadro a seguir:

Quadro 1 - Conjunto Ada e Edu: exemplares localizados

\begin{tabular}{|c|c|c|c|}
\hline Edição & Ano & $\begin{array}{l}\text { Número de } \\
\text { exemplares }\end{array}$ & Livro (s) \\
\hline $1^{\mathrm{a}}$ & $\begin{array}{l}1978 \\
1978\end{array}$ & $\begin{array}{r}1 \\
1 \\
\end{array}$ & $\begin{array}{l}\text { - Cartilha } \\
\text { - Cartilha }\end{array}$ \\
\hline $2^{\mathrm{a}}$ & - & - & - \\
\hline $3^{\mathrm{a}}$ & $\begin{array}{l}1978 \\
1979 \\
1980 \\
1980 \\
\end{array}$ & $\begin{array}{l}1 \\
1 \\
1 \\
1\end{array}$ & $\begin{array}{l}\text { - Cartilha } \\
\text { - Caderno de atividades } \\
\text { - Livro do professor } \\
\text { - Caderno de atividades }\end{array}$ \\
\hline $4^{\mathrm{a}}$ & 1980 & $\begin{array}{l}1 \\
5 \\
1\end{array}$ & $\begin{array}{l}\text { - Cartilha } \\
\text { - Cartilha } \\
\text { - Cartilha }\end{array}$ \\
\hline $5^{\mathrm{a}}$ & $\begin{array}{l}1981 \\
1981 \\
1981\end{array}$ & $\begin{array}{r}1 \\
1 \\
1 \\
4 \\
2 \\
30.000 \\
\end{array}$ & $\begin{array}{l}\text { - Cartilha }{ }^{12} \\
\text { - Livro do professor } \\
\text { - Cartilha } \\
\text { - Livro do professor (copyright de 1981) } \\
\text { - Livro do professor (copyright de 1981) } \\
\text { - Livro do professor (copyright de 1981) }\end{array}$ \\
\hline $6^{\mathrm{a}}$ & 1985 & 1 & - Cartilha \\
\hline \multicolumn{3}{|c|}{ Total de exemplares da cartilha } & 12 \\
\hline \multicolumn{3}{|c|}{$\begin{array}{l}\text { Total de exemplares do } \\
\text { caderno de atividades }\end{array}$} & 2 \\
\hline \multicolumn{3}{|c|}{ Total de exemplares do livro do professor } & 30.008 \\
\hline
\end{tabular}

Fonte: Material localizado nos seguintes acervos: a) Centro de Documentação/NUPED/ICHS/ UFMT; b) Biblioteca Nacional (RJ); c) Acervo da Bloch Editores; d) Arquivos pessoais das autoras da cartilha; e) Arquivo pessoal da autora deste texto.

Elaboração da autora.

11 O Programa do Livro Didático (PLID) abrangia os diferentes níveis de ensino: Programa do Livro Didático para o Ensino Fundamental (PLIDEF); Programa do Livro Didático para o Ensino Médio (PLIDEM); Programa do Livro Didático para o Ensino Superior (PLIDES) e Programa do Livro Didático para o Ensino Supletivo (PLIDESU).

12 Coedição Bloch/FENAME. 
Observando o número de edições, facilmente podemos concluir que, em seu primeiro ano na Bloch Editores, a cartilha teve três edições. Se considerarmos o mínimo por edição de 5 mil exemplares, registrado no contrato, chegaremos aos 15 mil exemplares da cartilha e provavelmente aos correspondentes 15 mil cadernos de atividades e 500 manuais do professor.

Um caderno de atividades encontrado na Biblioteca Nacional, da $3^{a}$ edição de 1979, com o carimbo de autorização do MEC para distribuição em 1/8/1983, sinaliza que houve, no ano de 1979 , pelo menos uma edição. Igualmente, no ano de 1980, o manual do professor, depositado na Biblioteca Nacional, evidencia mais uma edição de, no mínimo, 5 mil exemplares. Podemos observar que foram registrados como pertencentes à $3^{a}$ edição: a cartilha do ano de 1978; o caderno de atividades de 1979; e o livro do professor de 1980. Ao que tudo indica, embora esses três materiais compusessem o "conjunto Ada e Edu", foram tratados individualmente no processo de produção da editora, obtendo número e tiragem próprios de edição. Ainda, com registro do ano de 1980, consegui encontrar alguns exemplares da cartilha da $4^{a}$ edição.

Nesse cálculo, sempre lembrando ao leitor que trabalho aqui com o índice mínimo do qual tenho fontes para justificar, chegamos a um total de 30 mil exemplares publicados da cartilha, seguindo o raciocínio de que cada exemplar encontrado de uma determinada edição pertence a uma tiragem de 5 mil cartilhas.

Desse modo, chegamos ao ano de 1981 e à $5^{\text {a }}$ edição de $A d a$ e Edu, agora coeditada com a FENAME. Considerando que as determinações desse órgão previam que cada título selecionado tivesse um pedido mínimo de 7 mil exemplares por estado e de 20 mil para todo o país, poderia ficar com esse último número como tiragem mínima do ano em questão. No entanto, há outros indícios que precisam ser considerados.

O primeiro deles é a existência do dado emblemático de uma significativa sobra de estoque em um dos galpões da antiga TV Manchete, situado na Estrada da Água Grande, em Irajá, periferia do Rio de Janeiro, que abriga acervo significativo da Bloch Editores e que passarei a denominar "arquivo" da Bloch. ${ }^{13}$ Lá se encontra uma grande pilha de Ada e Edu - livro do professor. Os exemplares não traziam o número da edição, mas apresentavam o copyright de 1981, o que permite deduzir que eram referentes ao ano da coedição com a FENAME, quando a produção foi mais significativa. Um cálculo aproximado da pilha $(5 \times 10 \times 12=600$ pacotes, contendo 50 exemplares em cada um) me permite dizer que ali se encontravam cerca de 30 mil exemplares.

13 A Bloch Editores foi decretada massa falida em 2000. A minha visita ao seu acervo no Rio de Janeiro foi autorizada por Walter Soares, síndico da massa falida. Fui acompanhada pelo preposto Luiz Antônio Reis de Freitas. Este me informou que os livros contábeis da editora estavam sendo periciados e, portanto, eu não poderia ter acesso a eles. A inexistência de outros documentos (correspondências, contratos, notas fiscais) é explicada pela via da dispersão: hiato de tempo entre a notícia da falência e a falência, propriamente dita, e as constantes mudanças do acervo. 
Esse número, por si só, evidencia que, pelo menos no ano de 1981, a Bloch produziu bem mais que o mínimo rezado no contrato, que era de meros 5 mil exemplares, e também mais que o mínimo exigido pela FENAME, que era de 20 mil exemplares. Se considerarmos que para cada manual do professor eram confeccionadas cerca de 30 cartilhas para os alunos, nosso número cresce significativamente, evidenciando uma expectativa de produção de 900 mil exemplares de cartilhas, correspondentes àquele estoque de manuais do professor. Poderia mesmo ir além, levantando a seguinte hipótese: se esse material é sobra de edição, a produção do ano de 1981 foi muito significativa, extrapolando em muito as médias de $50 \mathrm{mil}$ exemplares por edição. Isso teria fundamento?

As fontes, sempre lacunares e imprevisíveis, vão se dando, lentamente, a conhecer, processo esse muitas vezes condicionado ao tempo disponível, à persistência, ao "faro" e à sorte do pesquisador. É nesse âmbito que situo o encontro de outro documento importante: A nova escolha do livro didático - Catálogo da FAE - Programa Nacional do Livro Didático (PNLD), de setembro de 1985. Na primeira página desse impresso, o presidente da FAE, Carlos Pereira de Carvalho e Silva, dirige-se aos professores traduzindo o que significava a palavra "Nova" para o PNL: o reconhecimento de "[...] que os professores têm o direito de indicar os livros que serão utilizados com seus alunos". O item "Começar de novo... vai valer a pena" traz a seguinte explicação:

Em agosto, você, provavelmente, participou da escolha dos livros de sua escola. Mas agora é preciso uma NOVA ESCOLHA, porque:

- Muitos professores e escolas pensaram que só podiam escolher livros dos catálogos de propaganda de algumas editoras!

- Muitas escolas indicaram seus livros em modelos de formulário não oficial, de propaganda de editoras!

- Muitos professores não foram consultados!

A FAE, no entanto, insiste:

- Sem Professor não há escolha! (Brasil, 1985, p. 3)

A indignação contida nas exclamações tenta, por um lado, justificar uma nova escolha no mesmo ano e, por outro, firmar o novo compromisso da FAE de que o professor seria o responsável pela escolha dos manuais e que, a partir de então, haveria menos interferências externas ao processo de escolha do livro didático.

Da página 3 à 8 , o catálogo se deteve a explicar toda a sistemática de escolha e preenchimento da ficha, justificando que "o computador vai ajudar" e, por isso, foi criado um código para cada livro. A partir da página 9 foram apresentados em tabelas e em ordem alfabética todos os títulos disponíveis para todas as séries "alfabetização", $1^{\mathrm{a}}$ a $4^{\mathrm{a}}$ - e todos os componentes curriculares: comunicação e expressão, matemática, estudos sociais e ciências. Para a $1^{\mathrm{a}}$ série, havia a especificidade de serem oferecidos os seguintes livros: cartilha, pré-livro e leitura intermediária. É exatamente na página 9 que figurava a cartilha $A d a$ e $E d u$, para escolha pelos professores brasileiros. 
Assim, a coedição Bloch/FENAME da cartilha Ada e Edu no ano de 1981, somada às evidências de sua distribuição pelo MEC no ano de 1983, e sua inclusão no catálogo da FAE do ano de 1985, para distribuição em 1986, me fazem defender a ideia de sua permanência no PLIDEF, pelo menos entre os anos 1981 e 1985, o que amplia consideravelmente as possibilidades de circulação desse livro didático.

Lamentavelmente, dada a ausência de outras fontes - tais como os contratos celebrados entre a FENAME/FAE e a Bloch Editores e os mapas de distribuição dos livros ou registros da distribuição específica desse livro didático - talvez seja possível ampliar para as instituições oficiais brasileiras o mesmo raciocínio que Darnton (1990) faz em relação aos editores: os arquivos são tratados como lixo.

Restam, então, as questões: Qual foi o montante de produção de Ada e Edu? Para onde, efetivamente, foram todos os exemplares produzidos pela Bloch Editores? Por onde circulou Ada e Edu?

Assim, preciso me conformar em "fazer o inventário dos arquivos do silêncio e fazer a história a partir dos documentos e das ausências dos documentos" (Le Goff, 2003, p. 103).

\section{CONCLUSÕES}

Estudar o "circuito das comunicações" do manual didático cartilha exigiu uma compreensão do papel da escola como instituição especializada em promover/ garantir o acesso das novas gerações à cultura letrada, com base no aprendizado da leitura e da escrita. Mortatti (2008, p. 93) lembra que na modernidade republicana

A alfabetização se tornou o fundamento da escola obrigatória, laica e gratuita; a leitura e a escrita se tornaram, "definitivamente", objeto de ensino e aprendizagem escolarizados, ou seja, submetidos à organização sistemática, tecnicamente ensináveis e demarcando preparação de profissionais especializados. Desse ponto de vista, a alfabetização se apresenta como o signo mais evidente e complexo da relação problemática entre educação e modernidade, tornando-se o principal índice de medida e testagem da eficiência da educação escolar.

"O signo mais evidente e complexo da relação problemática entre educação e modernidade" (idem, ibidem) - a alfabetização - historicamente se apoiou em cartilhas para cumprir seu papel de "chave" que abre a porta de entrada para a cultura escrita. Esses manuais galgaram tal nível de importância na alfabetização e na escolarização que passaram a ser sinônimo de método de alfabetização, o que evidencia a sua função instrumental (Choppin, 2004).

Assim, se a história da alfabetização se faz de embates sobre métodos "novos" e "antigos", aqueles, apoiados em "modernas verdades científicas", acusando estes, apoiados em teorias decadentes, de "tradicionais", a história de um livro de alfabetização reflete e refrata esse pressuposto.

Dessa maneira, o circuito das comunicações da cartilha Ada e Edu em suas fases de produção, difusão e circulação se amparou no discurso do novo em confronto 
com o velho e ultrapassado, fundando representações e moldando a cultura escolar, ao mesmo tempo, com elementos de transformação e de permanência.

Diante das urgentes demandas sociais daqueles tempos, em 1975 o governo federal propõe o II PSEC. Apelando para objetivos de modernização e melhoramento qualitativo, um quinhão de investimento é reservado à inovação e à renovação do ensino, que poderia mostrar toda a sua criatividade no seio do PNM. O "novo" nesse momento histórico era a aplicação dos pressupostos da teoria do capital humano (racionalidade, eficiência e produtividade), tida como eficiente para a administração de fábricas, para a escola, que passara a ter novas finalidades: atendimento a um novo público escolar - o povo brasileiro.

O conjunto de fontes disponíveis me encaminha para algumas interpretações possíveis. Por um lado, em termos de concepção de alfabetização, são ressaltadas duas crenças importantes da equipe: a) a esperança em poder materializar uma cartilha ideal do ponto de vista linguístico, utilizando-se uma linguagem regional e apresentando a língua de forma graduada, contemplando suas dificuldades e sua complexidade, a fim de que ela fosse de fácil manejo pelo professor e de melhor apropriação pelos alunos; b) com a definição dos objetivos e conteúdos inerentes à $1^{\mathrm{a}}$ série, a esperança de poder homogeneizar a aprendizagem das crianças.

Por outro lado, em termos da circulação do livro, Niskier ressalta e antecipa a dificuldade que teríamos, diante da dispersão dos arquivos da Bloch, de encontrar dados precisos da cartilha (edições, tiragens, localização etc.). No entanto, lembra que: "A cartilha foi adotada oficialmente em Mato Grosso. E aí teve uma boa circulação [...]. Em outros Estados, vendas pequenas [...]. A cartilha foi espalhada sobretudo nas regiões Norte e Nordeste".

Niskier faz referência a vendas pequenas, no entanto, sua visão comercial o levou a registrar no contrato, $4^{\circ}$ artigo, a possibilidade de a obra ser coeditada:

$\S$ único: Fica estabelecido, desde já, que se a obra for coeditada com o Instituto Nacional do Livro - INL, Fundação Nacional de Material Escolar FENAME ou outro órgão similar, os direitos autorais serão de apenas 6\% (seis por cento), para a tiragem da obra encomendada. (Bloch Editores, 1978, p. 1)

Assim, com base no modelo circuito das comunicações (Darnton, 1990), foi possível reconstruir aspectos da produção e da circulação da cartilha Ada e Edu no contexto mato-grossense e registrar algumas possibilidades da circulação desse material em âmbito nacional. Certo é que cedo constatei que o livro tem, em torno dele, muitos sujeitos. Mais que isso, ao tentar escrever a história de Ada e $E d u$, mergulhei, inesperadamente, na história da política pública que deu origem a essa cartilha - o PNM -, num claro exemplo de como a história da alfabetização se entrelaça com tantas outras histórias, como bem aponta Harvey Graff (1994, p. 174). Ambos, projeto e livro, traduzem concepções de educação e de alfabetização, sugerem metodologias e práticas pedagógicas, configurando uma cultura escolar, cujos tentáculos ainda se fazem presentes. 


\section{REFERÊNCIAS}

Amâncio, Lázara Nanci de Barros. Ensino de leitura e grupos escolares: Mato Grosso (1910-1930). Cuiabá: EdUFMT, 2008.

Batista, Antônio Augusto Gomes. Um objeto variável e instável: textos, impressos e livros didáticos. In: Aвreu, Márcia (Org.). Leitura, história e história da leitura. Campinas: Mercado de Letras; ALB; São Paulo: FAPESP, 2002. p. 529-575.

Bloch Editores. Contrato de edição. Rio de Janeiro: [s.n.], 1978.

Brandẽo, Zaia; Baeta, Anna Maria Bianchini; Rocha, Any Dutra Coelho da. Evasão e repetência no Brasil: a escola em questão. Rio de Janeiro: Achiamé, 1983.

Brasil. MEC/INL. Programa Nacional do Livro Didático. Brasília: MEC/INL, [197-?]. . II Plano Setorial de Educação e Cultura (1975/1979). Brasília: MEC, 1976. . MEC/FAE. A nova escolha do livro didático. Rio de Janeiro: MEC/FAE, 1985. . MEC/INEP/SEEC. Informe Estatístico 1996-2002. Brasília: MEC/INEP/ SEEC, 1996-2002.

Burke, Peter. O que é história cultural? Rio de Janeiro: Jorge Zahar Ed., 2005.

CARdoso, Cancionila Janzkovski. Cartilha Ada e Edu: produção, difusão e circulação (1977-1985). Cuiabá: EdUFMT, 2011.

Chartier, Roger. A bistória cultural: entre práticas e representações. Lisboa: DIFEL; Rio de Janeiro: Bertrand, 1990.

Chervel, André. História das disciplinas escolares: reflexões sobre um campo de pesquisa. Teoria Ė Educação, Porto Alegre: Pannonicas, n. 2, p. 177-229, 1990.

Choppin, Alain. História dos livros e das edições didáticas: sobre o estado da arte. Educação e Pesquisa, São Paulo: USP, v. 30, n. 3, p. 549-566, set./dez. 2004.

CorrêA, Rosa Lydia Teixeira. O livro escolar como fonte de pesquisa em história da educação. Cadernos CEDES, Campinas: CEDES, v. 20, n. 52, p. 11-24, nov. 2000. (Cultura escolar: história, práticas e representações)

Darnton, Robert. O beijo de Lamourette: mídia, cultura e revolução. São Paulo: Companhia das Letras, 1990.

Frago, Antônio Viñao. Alfabetização na sociedade e na história: vozes, palavras e textos. Porto Alegre: Artes Médicas, 1993.

Graff, Harvey J. Os labirintos da alfabetização: reflexões sobre o passado e o presente da alfabetização. Porto Alegre: Artes Médicas, 1994.

Hallewell, Laurence. O livro no Brasil: sua história. São Paulo: T. A. Queiroz; Ed. da Universidade de São Paulo, 1985.

Höfling, Eloisa. Notas para discussão quanto à implementação de programas de governo: em foco o Programa Nacional do Livro Didático. Educação E̋ Sociedade, Campinas: CEDES, ano XXI, n. 70, p. 159-170, abr. 2000. 
Julia, Dominique. A cultura escolar como objeto histórico. Revista Brasileira de História da Educação, São Paulo: SBHE; Campinas: Autores Associados, n. 1, p. 9-42, jan./ jun. 2001.

Lajolo, Marisa; Zilberman, Regina. Livro didático, matéria da literatura. In: A formação da leitura no Brasil. São Paulo: Ática, 1998. p.120-128.

Le Goff, Jacques. História e memória. 5. ed. Campinas: Ed. da UNICAMP, 2003.

Mato Grosso. Projeto Novas Metodologias Aplicáveis ao Processo Ensino Aprendizagem para o Ensino de $1^{\circ}$ Grau. Cuiabá-MT: SEDUC, 1976.

. Projeto Novas Metodologias Aplicáveis ao Processo Ensino Aprendizagem para o Ensino de $1^{\circ}$ Grau. Cuiabá-MT: SEDUC, 1977a.

.SEDUC/Projeto Novas Metodologias. Exposição de motivos, n. 2. Mato Grosso: SEDUC, 1977b.

. Projeto Novas Metodologias Aplicáveis ao Processo Ensino Aprendizagem para o Ensino de $1^{\circ}$ Grau. Cuiabá-MT: SEDUC, 1979a.

. SEDUC/Projeto Novas Metodologias. Projeto III Encontro Estadual de Alfabetização. 11f. 1979b. Datilografado.

Mortatti, Maria do Rosário Longo. Os sentidos da alfabetização (São Paulo/1876-1994). São Paulo: Editora UNESP; COMPED, 2000.

. A "querela dos métodos" de alfabetização no Brasil: contribuições para metodizar o debate. Revista ACOALFAPLP - Acolhendo a Alfabetização nos Países de Língua Portuguesa, São Paulo: USP, ano 3, n. 5, p. 91-114, 2008. Disponível em: <http://www. acoalfaplp.net>. Acesso em: set. 2008.

Oliveira, João Batista Araújo; Guimarães, Sonia Dantas Pinto; Bomeny, Helena Maria Bousquet. A politica do livro didático. Campinas: Summus; UNICAMP, 1984.

Persona, Rosa Maria Jorge; Maciel, Renete M. de Almeida; Fernandes, Maria Antonieta; Araújo, Regina Lúcia Borges; Almeida, Lúcia Elvira Rogolin de; Marques, Francisca Amélia; Silva, Ana Maria Dias. Ada e Edu: livro do professor. Rio de Janeiro: Bloch Editores, 1978.

. Ada e Edu: caderno de atividades. Rio de Janeiro: Bloch Editores, 1978.

Ada e Edu: para classes de alfabetização. Rio de Janeiro: Bloch Editores, 1978.

Rosemberg, Fúlvia; Bazilli, Chirley; Silva, Paulo Vinícius Baptista da. Racismo em livros didáticos brasileiros e seu combate: uma revisão da literatura. Educação e Pesquisa, São Paulo: USP, v. 29, n. 1, p. 125-146, jan./jun. 2003. Disponível em: <http://www. scielo.br/pdf/ep/v29n1/a10v29n1.pdf>. Acesso em: 16 set. 2008.

SAvianı, Dermeval. Breves considerações sobre as fontes para a história da educação. In: Lombardi, José Claudinei; Nascimento, Maria Isabel Moura (Org.). Fontes, história e historiografia da educação. Campinas: Autores Associados; HISTEDBR, 2004. p. 1-20.

Soares, Magda; Maciel, Francisca Pereira. Alfabetização: estado do conhecimento. Brasília: INEP/COMPED, 2000. 


\section{SOBRE A AUTORA}

Cancionila Janzkovski Cardoso é doutora em educação pela Universidade Federal de Minas Gerais (UFMG). Professora associada da Universidade Federal de Mato Grosso (UFMT).

E-mail:kjc@terra.com.br

Recebido em maio de 2011

Aprovado em novembro de 2011 


\section{CANCIONILA JANZKOVSKI CARDOSO}

\section{Cartilha Ada e Edu: de produção regional à circulação nacional (1977-1985)}

O texto apresenta resultados de pesquisa cujo objetivo geral foi o de contribuir para a sistematização e socialização da história de um livro mato-grossense, mediante a investigação da produção, difusão e circulação da cartilha $A d a e$ Edu, elaborada em 1977. A investigação se inscreve na história da alfabetização, sendo orientada por referenciais teórico-metodológicos ligados à história cultural e à história dos livros. A proposta metodológica baseou-se no circuito das comunicações, modelo proposto por Robert Darnton, para examinar o percurso da cartilha regional Nossa terra nossa gente, posteriormente transformada em cartilha $A d a$ e $E d u$, editada e comercializada nacionalmente pela Editora Bloch. Foi possível reconstruir aspectos da produção e da circulação dessa cartilha no contexto mato-grossense e registrar elementos da circulação em âmbito nacional, via Programa Nacional do Livro Didático.

Palavras-chave: história da alfabetização; cartilhas escolares; circulação de livros. 


\section{School primer Ada and Edu: from regional production to national circulation (1977-1985)}

The text presents results of a study whose main goal was to contribute to the systematization and dissemination of the history of the book of Mato Grosso state, by investigating the production, diffusion and circulation of the school primer Ada and Edu, created in 1977. The study falls into the category of history of literacy, and is guided by theoretical and methodological frameworks linked to cultural history and book history. The methodological proposal has arisen from the communications circuit, a model proposed by Robert Darnton, to examine the course of the regional school primer Nossa terra nossa gente, subsequently changed to school primer Ada and Edu, published and marketed nationwide by Editora Bloch. It was possible to reconstruct aspects of the production and circulation of that school primer in the context of Mato Grosso state and record elements of nationwide circulation through Programa Nacional do Livro Didático (PNLD, National Textbook Program).

Keywords: history of literacy; school primers; circulation of books.

\section{Cartilla Ada y Edu: de producción regional a la circulación nacional (1977-1985)}

El articulo presenta los resultados de un estudio cuyo objetivo general es contribuir a la sistematización y difusión de una historia del libro de Mato Grosso, tras la investigación de la producción, difusión y circulación de la cartilla Ada e Edu, elaborada en 1977. La investigación se inscribe en la bistoria de la alfabetización, y se guia por las referencias teóricas y metodológicas relacionadas con la historia cultural y la historia del libro. La propuesta metodológica se basó en el circuito de las comunicaciones, modelo propuesto por Robert Darnton, para examinar la ruta de la cartilla regional Nuestra tierra nuestra gente, más tarde transformada en la cartilla Ada y Edu, editada y comercializada a nivel nacional por la Editora Bloch. Ha sido posible reconstruir aspectos de la producción y la circulación de esta cartilla en el contexto de Mato Grosso y registrar elementos de la circulación a nivel nacional, por medio del Programa Nacional do Livro Didático.

Palavras clave: historia de la alfabetización; cartillas escolares; circulación de libros. 